\title{
Wheat and chaffs in the interpretation of the current COVID19 outbreak in Italy
}

\author{
Salvatore Chirumbolo ${ }^{1,2,3}$ (D) Geir Bjørklund ${ }^{2}$
}

Received: 28 March 2020/ Accepted: 24 May 2020/Published online: 5 June 2020

(C) Indian Virological Society 2020

\begin{abstract}
The COVID19 outbreak in Italy is still a big concern. The Italian Government has recommended citizens to respect faithfully any compulsory legal disposition in order to stay home and so contributing in escaping viral contacts and slowing down epidemic. Emergency has raised a widely animated debate about how to read and comprehend the daily case numbers, the medical and caregivers availability, the needs to swab asymptomatic subjects. In this review the authors discuss about the many wheat and chaffs of how this virus disease is addressed.
\end{abstract}

Keywords COVID19 - Coronavirus · Italy · Swabbing · Lockdown

\section{Introduction}

While having a look at the official map of the worldwide COVID19 outbreak on January 29th 2020, one can realize that SARS-CoV2 infected subjects were first reported in Germany and France, whereas in Italy this occurred in a second instance, although only few days later, on January 31 st 2020 [1, 2]. The number of official cases in Germany was completely negligible throughout the period January 29th 2020 to the end of February, while in the first ten

Salvatore Chirumbolo

salvatore.chirumbolo@univr.it

1 Department of Neurosciences, Biomedicine and Movement Sciences, University of Verona, Verona, Italy

2 Council for Nutritional and Environmental Medicine (CONEM), Mo i Rana, Norway

3 CONEM Scientific Secretary, strada Le Grazie 9, 37134 Verona, Italy years of March a significant number of cases (100-250) has began to occur, reaching the number of 22,364 cases so far (Fig. 1) [3]. This time lapse was yet particularly concerning for Italy, which has reached the worrisome number of 53,578 cases on March 20th 2020, while we are writing, starting from only the second half of February, so compelling the Italian Government to engage a burdensome and severe decision on the citizens' lifestyle. It may appear particularly puzzling how come Italy reached this bulk of infected people so far while other industrialized, democratic countries, even in the Western regions of the planet, are currently counting a very modest amount of cases despite their huge presence of resident and passing Chinese people (Fig. 1). Taking into consideration that the SARS-CoV2 rapidly widespreads within an actively crossinteracting population of subjects, who are potentially positive for the presence of SARS-CoV2 genomes in the upper respiratory tracts, Germany should have crucial concerns about local healthcare and hospitalization capability just in current March days. This would be particularly urgent in the resuscitation and cardio-pulmonary units, at least since February 10th 2020, if accounting on the calculation held by some authors considering the SARS-CoV2 replication rates [4]. Obviously, Germany is only one of the many examples regarding European countries, if we except Italy. Briefly speaking, one should wonder why the SARS-CoV2 infecting German people was completely quiet from a clinical relevance for at least one month and why German physicians did not raise any outcry for excessively crowded hospitals.

Some possible explanations of this "pseudo-window" phase might be that (a) SARS-CoV2 can rapidly undergo an immune clearance and elicit an immune serum conversion, though in a lesser extent in elderly people, leading to mismatching a COVID19 with a severe flu; (b) deaths 


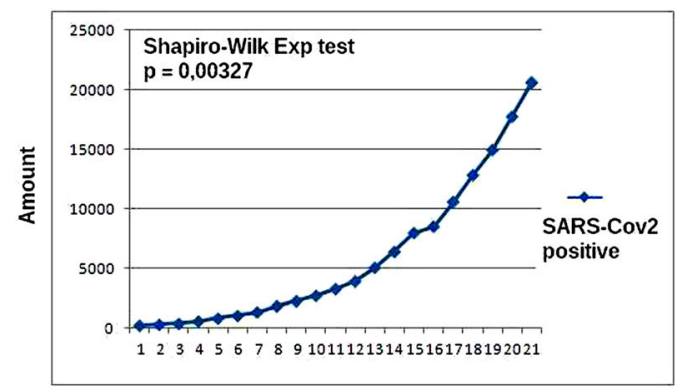

A

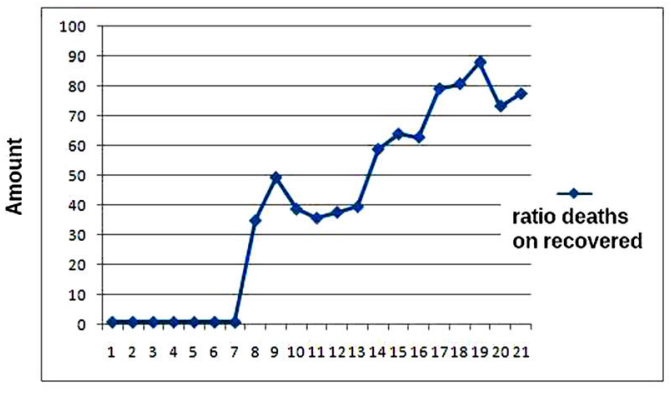

C

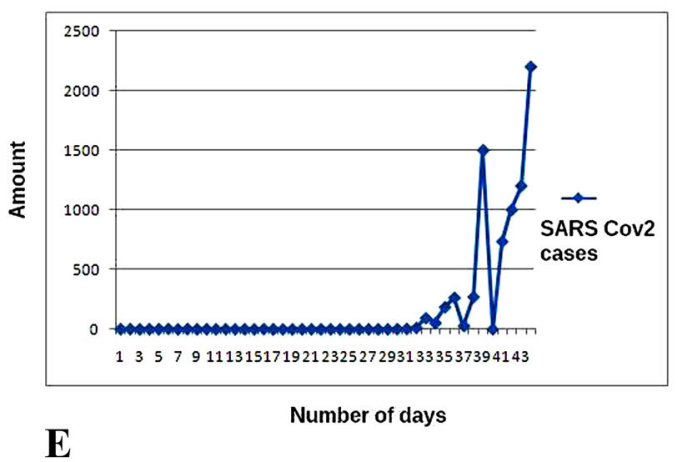

Extrapolation fit of exponential
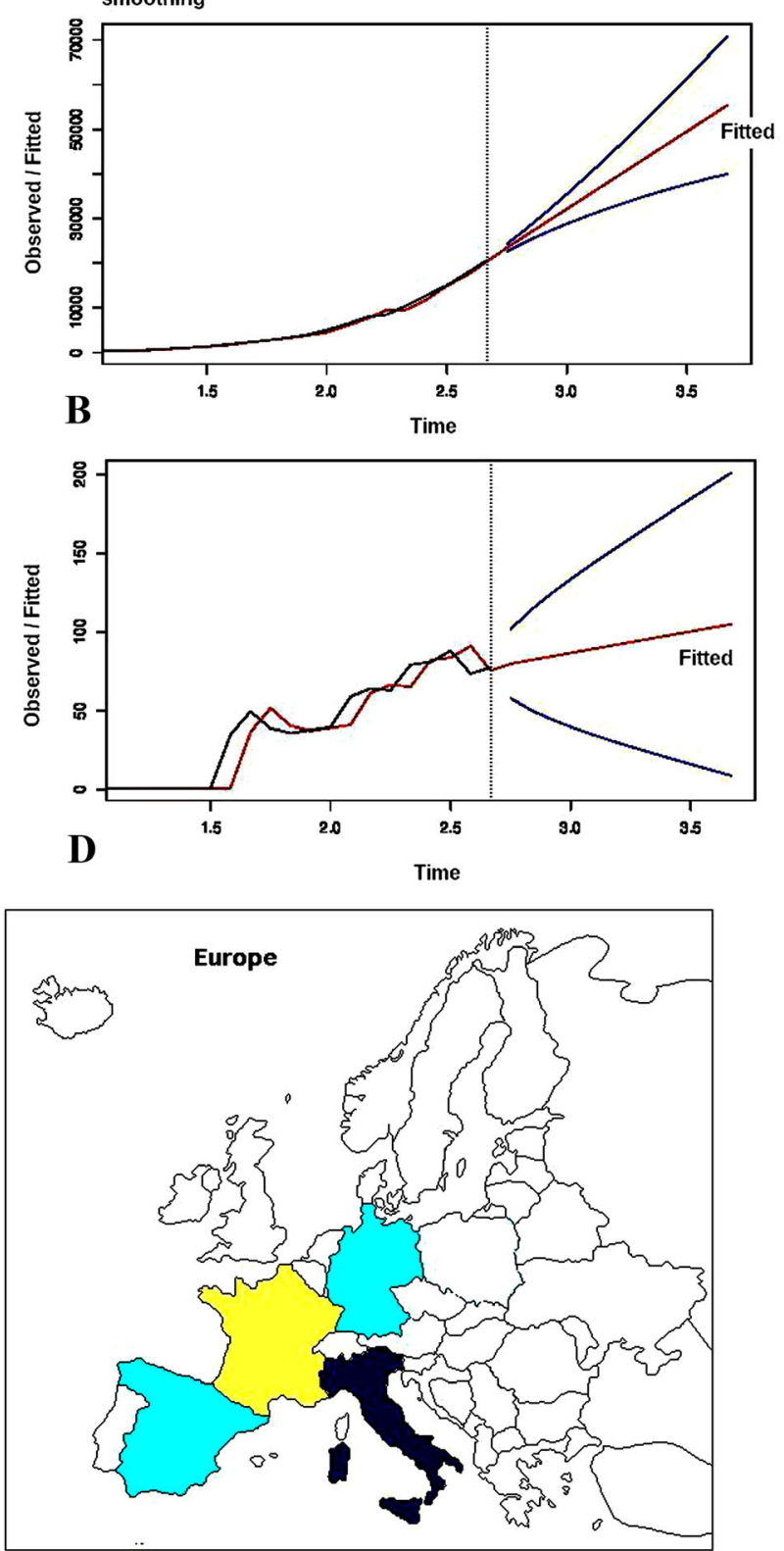

$\mathbf{F}$

$>50,000$

20,000-30,000

$<20,000$

March 15th 2020); D Extrapolation fit of exponential smoothing (double Brown model) on data from plot C; E Graph showing positive cases in Germany on March 15th 2020; F Map of COVID19 cases in Europe ( source WHO public data, on March 15th 2020)

swabs mounting any day on are mis-interpreted as occurring dynamically in the same time course of the resulting tests. Briefly speaking, the increase in positive tests is unequivocally mis-interpreted for an increase in currently active infected people. 
To verify this latest point, a Shapiro-Wilk test on the very recent data in Italy has been performed to assess if the plotted distribution of the number of cases/day is exponential or linear (Fig. 1). Exponentiality in the cases distribution should highlight an underneath mechanism of active infection, while a non exponential or linear progression of data would mean that PCR analyses are catching increasing clusters of positive subjects from a homogeneously infected population, where the SARSCOV2 is much probably quiescent or symbiotic in the upper respiratory tracts of people. The linear (proportional) distribution should enlight a static circumstance, while the exponential distribution a dynamic circumstance, i.e. SARS-CoV2 while infecting people.

The Shapiro-Wilk exponential test for the number of cases in Italy from the week March 2st 2020 to March 9th 2020 , has a $p=0.442847$, which is out of the range $p_{0.025}$ $\alpha=0.0537$ to $p_{0.975} \alpha=0.3454$, so describing a non exponential distribution. This trend was even confirmed by elaborating data from February 24th to March 15th 2020 ( $p=0.00326944$, which is out of the range $p_{0.025}$ $\alpha=0.0250$ to $p_{0.975} \alpha=0.1054$, so describing a non exponential distribution, i.e. a distribution with asymmetrical right/positive skew (skewness $=1.150188$, excess kurtosis $=0.312139)$ (Fig. 1A).

The calculation of Shapiro-Wilk test for exponentiality is derived from:

$W(E)=\frac{n\left(\bar{X}-X_{\min }\right)^{2}}{[(n-1) s]^{2}}$

where $s$ is the sample standard deviation, $X_{\min }$ is the minimal number (value) in the data set and $n$ is the sample size [5].

This distribution trend does not allow to foresee a possible forthcoming scenario, as it does not follow a Gaussian behaviour. Using a time series forecasting smoothing method, able to use models fitting on historical data and to predict future observations, a forecasting of data plotted in Fig. 1A (double exponential smoothing or Brown model) shows that the alpha parameter (or $\alpha$ smoothing factor) for a multiplicative seasonality was $\alpha=0.74961785$, giving a plot where the $\mathrm{IC}_{95}$ confidentiality prevision was an increasing linearity upon the time course (Fig. 1B). The number of deaths, purported for COVID19, shows an increase respect to recovered, healed patients (Fig. 1C), expecting a forecast double smoothing (Brown model) where this trend would tend to a very modest increase, i.e. a balanced ratio $(\alpha=0.04601992)$ (Fig. 1D) [6]. This evaluation would suggest that the distribution of positive subjects, considered as infected individuals, does not fit an exponential trend and therefore that no possible epidemic maximum will be reached, unless the number of COVID19 caused deaths reduces their bulk due to ancillary independent factors (microenviroment, seasonality, viral biology, etc.), despite the many restraint commitments known as lockdown.

Obviously it is noteworthy to admit that few data may not highlight the "real" distribution trend in order to assess an exponentiality due to a current infectious dynamics within the population. Yet, it could represent a way by which data are actually distributed and exponentiality does not appear taking into consideration the burden of cases in the crucial week March 2nd-March 9th 2020 in Italy, which compelled the Prime Minister to hold severe dispositions and start the lockdown with its restrictions.

Moreover, although considering that elderly people are highly subjected to SARS-CoV2 severe pulmonary infections, the mortality rate on the whole over 65 yrs population (13.5 millions people) is curremtly $\leq 0.005 \%$, following recent Italian official Government data, while it reaches $7.886 \%$ on the total of positive subjects (data: from March 15th, 2020), very close to 2003 SARS outbreak. As the increasing delta between two different case numbers in two separate contiguous days is quite constant (20-22\%), it may be conceivable that this enhancement depends on the increasing, cumulating number of performed tests, as any total bulk of carried out analyses, catches the same representative sample of subjects from a SARS-CoV2 homogeneously infected population, where negative subjects can be mainly individuals having undergone a viral clearance. This occurrence should suggest that in the absence of swabs performed, the whole society cannot have any worrisome awareness that something is occurring underneath, as patients might be mis-diagnosed for flu or other respiratory pathology. And it cannot be excluded that Europeans may have undergone the outbreak peak very early respect to the present expectation.

Therefore, scientists should wonder if the linear (proportional) increase in SARS-CoV2 positive subjects on the daily time course is a function of the increase in rhynopharyngeal swabs rather than of the increase in infectious people-to-people contacts. Moreover, scientists must wonder why more than $97 \%$ of the SARS-CoV2 and more than $94 \%$ of COVID19-caused deaths are widespread in the sole Northern regions of Italy. Some fundamental comorbidities are also supposed.

The more correct evaluation of the SARS-CoV2 epidemiology should help politicians to better enterprise fundamental decisions in order to prevent people from being damaged by social and economic burdens. 


\section{The pulmonary microbiome and SARS-CoV2 opportunistic pathogenesis: why this issue is yet dismissed from debating?}

The great bulk of SARS-CoV2 positive subjects and deaths from COVID19 is currently being reported in Lumbardy, a highly urbanized Northern region of Italy particularly crowded of resident people from different nationalities. The recent data from the Italian authorities are describing a scenario where more than 94\% of all COVID19 cases are located in the Northern part of Italy, particularly known for the existence of a significant environmental pollution $[7,8]$. Figure 2 shows that both nitrogen dioxide $\left(\mathrm{NO}_{2}\right)$ concentration levels and $\mathrm{PM}_{10}$ particulate matters were already particularly concerning in 2016 in Lumbardy, which is now enumerating the highest number of COVID19 cases. Actually, Carugno et al., stated that Lumbardy is one of the most polluted area in Europe [8]. According to the authors, natural mortality can be associated with both major pollutants, namely $\mathrm{NO}_{2}$ and $\mathrm{PM}_{10}$, where $\mathrm{PM}_{10}$ was associated with highest mortality for pulmonary pathologies $(1.64 \% \quad 90 \%$ CrI (Credibility Interval), $\mathrm{IC}_{95}$ 0.35-2.93) [8]. The relationship between $\mathrm{PM}_{10}$ and pulmonary disease may be particularly intriguing to assess the etiopathogenesis of COVID19 in Northern Italy. While the commonest consideration about SARSCoV2 is its very rapid ability in widespreading within an active breathing population and to mainly hit elderly people having severe comorbidities (type 2 diabetes, hypertension, chronic inflammatory illness, cardiovascular disorders), one possibility is that SARS-CoV2 is an opportunistic pathogen, acting alongside with antibioticsresistant bacterial strains, which can overwhelm host's immunity and cause an acute, severe interstitial pneumonia [9-11]. Environmental nanoparticulates, xenobiotics and $\mathrm{PM}_{10}$ can severely danage lungs and, associated with $\mathrm{NO}_{2}$,

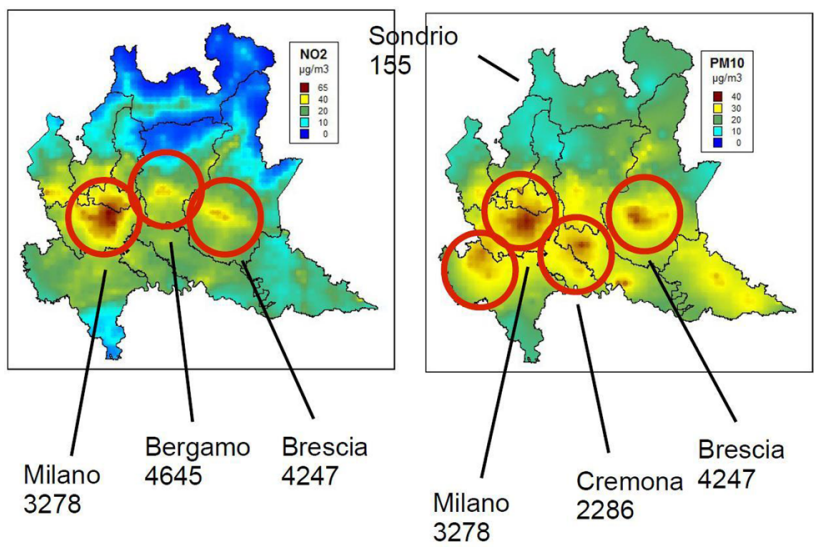

Fig. $2 \mathrm{NO}_{2}$ (left) and $\mathrm{PM}_{10}$ (right) pollution in Lumbardy with the main towns and the number of deaths updated to March 20th 2020 (data from Dr W. Mango, projections 2016-2019, for courtesy) can promote idiopathic pulmonary fibrosis [12]. According to Wuyts and colleagues the differential diagnosis of usual interstitial pneumonia from pneumonias coming from air pollution, such as idiopathic pulmonary fibrosis (IPF) [12], may be biased, if simply performed with a chest computing tomography (CT), due to the existence of further very similar lung pneumonias caused by or assoiated with chronic hypersensitivity pneumonitis, collagen vascular disease, drug toxicity, asbestosis, familial IPF and Hermansky-Pudlak syndrome [13]. On the sole basis of the available number of cases, updated to March $23^{\text {rd }} 2020$, hospitalized patients and pneumonia-caused deaths without any further patient statistic stratification, have interesting positive predictive values. Bayesian calculation in Lumbardy about the positive predictive value that a subject undergoing intensive therapy had really a COVID19caused pneumonia based on swab test and chest CT was $12.9224 \%$, (negative $=5.8381 \%$ ), whereas the positive predictive value (PPV) on the hospitalized COVID19 positive population was $19.3986 \%(\mathrm{NPV}=3.6820 \%)$. This may suggest that only one fifth of hospitalized patients in the intensive care units might be correctly diagnosed for COVID19. The calculation on pneumonia-caused death $\mathrm{PPV}=15.1887 \%, \mathrm{NPV}=3.1352 \%$, meaning that deaths for COVID19 have about one sixth of possibility to be really identified as COVID19-caused mortality. Without an anatomic-pathological and molecular post mortem evaluation of COVID19, which dramatically lacks in Italy, it is very difficult to ascertain how many deaths must be surely attributed to a SARS-CoV2 infection, rather than to further co-morbidities. Obviously, these data should be adjusted on the actual performance scores of chest CTs and qPCRs in Lumbardy, as well in Italy, a bulk of data yet lacking so far. Furthermore, recent studies have assessed that serum immuno-globulins profiles in the COVID19 diagnosis increase the positive detection rate when associated with RT-qPCR (98.6\%), respect to the simple RT-qPCR by alone (51.9\%) [14].

The possibility that the reported deaths for COVID19 are biased because of the existence of pneumonia cases caused by diverse ethiology depends also on the numerous, quite frequent analytical errors. For example, the way by which rhino-pharyngeal swabs are made, as lower respiratory tract are much more positive for the presence of SARS-CoV2, may affect the RT-qPCR result [15]. Moreover, sensitivity of CT to diagnose an interstitial pneumonia was closely related to SARS-CoV2 positivity (97\%), respect to a $75 \%$ for SARS-CoV2 negative individuals [15].

Co-morbidities in COVID19-caused bilateral interstitial acute and severe pneumonia, i.e.an acute respiratory distress syndrome (ARDS) may have a role much larger than expected before. A possibility to shed light on COVID19 
ethiopathogenesis might come from evaluating possible impairment in the pulmonary microbiome. According to some author, the majority of the interstitial lung diseases (ILDs) are idiopathic, as aside from interstitial pneumonia caused by systemic disorders such as dermatomyositis and rheumatoid arthritis, many ILDs are associated with unknown immune dysfunctions in the lung [16-18]. In this context, both environmental bacteria and fungi may be triggering agents in causing ILDs [19, 20]. Therefore, when microbiological agents and xenobiotic pollutants co-work in causing a lung interstitial damage, it can be speculated that SARS-CoV2 has much higher possibility to lead to ARDS [21, 22]. The pulmonary microbiome might play a role of the utmost importance in this context. Bacteria population in the lung microbiota, its impact in the number of variable species and composition, depends on the ability of bacteria to migrate from nose and mouth via the mucociliary clearance mechanisms and the local immunity, so depending on both the external room microenvironment with its sepsis and one's own competent immunity. Many bacteria or fungi from nosocomial origin may alter the pulmonary microbiome, which is usually represented by species from the genus Streptococcus, Prevotella and Veillonella, whereas in IPF patients pathogenic strains from the genus Haemophilus, Streptociccus and Neisseria may replace resident bacterial species usually tolerated by the local immunity [16, 23-25]. The ethiopathogenesis of COVID19 in this circumstance can be quite exclusively speculated on the basis of SARS-mediated ARDS [26]. Viral replication in the lungs is associated with a rapid increase in pro-inflammatory cytokines, such as TNF- $\alpha$ and IL-6 but also with innate immune cell-recruiting chemokines, such as CXCL10, CCL2, CCL3 and CCL5, which enhance the transmigration of NK cells, plasmacytoid dendritic cells and macrophages in the lungs [26]. Usually, this occurs within 2-3 days (median 5.1 days) following the coronavirus entry into the lung and anyway after 2 days of intranasal administration in laboratory animals [26]. In these models, a week later the lung proinflammatory response a second wave of enhanced production of cytokines (IFN- $\gamma$, TNF- $\alpha$, IL-6, IL-1 $\beta$, IL-2, IL5) and chemokines and their receptors (CXCL10, CXCR3, CXCL9, CCL2, CCR2, CCR5, CCL3, CCL5) can be found in the ill lungs [26, 27]. Following data from 2003-2004 SARS outbreak, it is noteworthy to claim that the Italian Government reported only 4 official deaths in 2003 caused by SARS [28, 29], quite far from the thousands of victims purported to be associated to date with SARS-CoV2 infection.

If SARS-CoV2 is an opportunistic pathogen, any impairment in the pulmonary microbiome might promote viral access into the lung interstitial parenchyma and cause ARDS. Environmental pollutants, lung colonizing micro- organisms and xenobiotics can profoundly disturb or damage this microbiota [30-32]. Although ARDS can be caused by different causes, a possibility investigated in laboratory animals and isolated perfuse lungs reported that endotoxin, able to produce lung injury, greatly enhance cytokine production and iNOS genetic expression, leading to a nitric oxde (NO)-mediated toxicity [33]. Interestingly, studies reported in SARS showed that NO should inhibit viral replication as by reducing the palmitoylation of early spike (S) viral proteins, so affecting the recognizing with its cognate ACE receptor [34]. However, while NO seems to reduce the viral replication cycle, the possible cytokine "storm" induced by viral immunity and bacteria, might be a causative factor of ARDS. The possible hypothesis to be forwarded in COVID19 pathogenesis is that, while angiotensin converting enzyme 2 (ACE) protects lungs from injury, SARS-CoV2 interacting with ACE receptors, prevent $\mathrm{ACE}$ to protect lungs from severe acute respiratory distress or failure [35]. This should allow people to comprehend the fundamental importance of the many environmental sepsis procedures so far recommended.

\section{Rhynopharyngeal swabs and the concern of the COVID19 asymptomatic subjects}

The highly debated issue about COVID19 asymptomatic subjects asks for some further elucidation. A first consideration to be pointed out is the risk factor to get COVID19 sickness standing the current lockdown situation in Italy. Infections are limited to in-house contacts. The risk index (RI) to die for COVID19 being positive in the current days in Italy is 2.457829 ( $\mathrm{IC}_{95}=2.409-2.508$ ), based on March 23rd 2020 data series. This IR value comes from elaborating the current available Ministry of Health publicly reported data on the COVID19 outbreak and should be adjusted for the outcome of hospitalized patients due to excellence in healthcare units and to the amount of in house quarantined people. The IR value to be infected with SARS-CoV2 without lockdown is $13.683,379$ ( $\mathrm{IC}_{95}$ $=13.456-13.914)$, with the current lockdown IR = $6.243,932\left(\mathrm{IC}_{95}=6.133-6.357\right)$, taking into account data on March 23rd 2020. These estimations are yet presumptive, as they should be adjusted on the actual Basic Reproduction Number or R0 calculated upon a lockdown scenario rather than an open-wide contacting one. The R0 evaluated for SARS-CoV2 is still a matter of debate [36]. According to some authors it ranges from 1.4 to 3.9 [37-39]. Starting from a first WHO estimation of 2.0-2.5 in China outbreak [40], the use of the Incidence Decay and Exponential Adjustment by Majumder and colleagues reaches a R0 value of 2.0-3.3 [36], whereas the current akcnowledged R0 for SARS-CoV2 has been established 
corresponding to 2.28-3.0, very close to the SARS R0 [36]. This R0 value means that the ability of SARS-CoV2 to infect can be measured as follows: a single person $x$ can infect $3^{x}=3^{1}=3$ different people, while 10 different subjects $x$ can infect $3^{10}=59,049$ people, in a wide-open contact. According to this calculation, an average of 8 individuals $(7.97,553)$ with SARS CoV2 $\mathrm{R} 0=3$ most probably started infections in the wide open contact, before the first Government lockdown disposition (March 4th, 2020). Therefore, taking into account the bulk of positive subjects in Italy reached at March 25th $2020(74,386)$ and maintaining the same number of contacts, we investigated if R0 slowed down, because of the lockdown. Actually, the SARS-CoV2 theoretical R0 nay be decresed from the theoretical $\mathrm{R} 0=3$, to $\mathrm{R} 0=1.82482$. Standing this evaluation, in the lockdown circumstance 10 people can infect only 409 subjects (409.45), at least theoretically, so assessing the effectiveness of the restrictive social measures. However, it is impossible to forecast the new SARS$\mathrm{CoV} 2 \mathrm{R} 0$ value on the basis of the daily progress in positive (infected) subjects, because, if any, we might observe only an "apparent" reduction in R0 attributed to the lockdown, yet actually SARS-CoV2 virulence should decrease due to further biological causes. Furthermore, we are considering an epidemlogical model based on the COVID19 Chinese outbreak, without considering the significant diversity in the social, cultural, economic and environmental habits respect to Italians.

While lockdown has the crucial purpose to dampen dramatically the probablity to be infected by lowering the number of inter-human contacts, the selective pressure on viral spreading and its virulence may be significantly reduced. This would mean that COVID19 case distribution, if normal, will have a low degree of kurtosis $(<3)$, most probably generating a platykurtic curve, rather than a leptokurtic one with a skinny vertical range. But, if this solution may have the merit to weak substantially the SARS-CoV2 virulence within the population, the economic and social burden is particularly cumbersome, due to the longer lockdown time.

One must admit that houses are much more hazardous that an open air environment, due to the highest probability to be infected in a relatively finite volumetric espace, where virus containing aerosols easily stay long on in room surfaces [41]. Therefore, with a SARS-CoV2 R0 $=3$, supposed a condominium with 30 apartments, each hosting an average of 4 individuals and using the lift to go downstairs to the cellar or outside the building, the possibility to infect all residents without individual protection devices (IPDs) such as FFP2 masks, may be particularly worrisome. Moreover, if at least only 4 persons are SARS$\mathrm{CoV} 2$ positive and asymptomatic in the prodromic stage of the disease, at least 81 subjects/120 (67.5\%) will be infected in a short time, depending on the frequency with which residents in the building use the lift or the stairs to go out from their own flats. The issue of SARS-CoV2 asymptomatic individuals is still a concerning matter of debate, in particular if one should consider that both paucisymptomatic prodromic and convalescent asymptomatic SARS-CoV2 positive people are potentially infectious, when meeting other people who are coronavirus negative. Mapping all SARS-CoV2 positive subjects is one of the main objectives of some regional governments in Italy, which are claimed to following the Korea method [9, 42-47].

However, performing a huge amount of rhynopharingeal swabs and RT-qPCR, each being time consuming ( $4 \mathrm{~h}$ average) and expensive, may be really burdensome for citizens and economics. Any shortage in swabs endowed with inactivating virus devices, are a potential hazard for operators, who are compelled to enhance the cumbersome safety measures. Therefore, the politics to compel asymptomatic people in undergoing a COVID19 swab RT-qPCR test appears quite impracticable, pending this dramatic situation in Italy.

Accrding to prospective Bayesian evaluations based on 27th March 2020 data [48, 49], if Italians as a whole would be swabbed in one single day, the actual estimated number of SARS-CoV positive, asymptomatic subjects with compulsory in-home prescription might be as high as 5.6 millions $\left(\mathrm{IC}_{95}=4.8-6.1\right)$. This perspective should engage swabbers for an average period lasting 485 days, with the current swabs/day, i.e. about one year and four months, just the time range planned to earn a vaccine. Obviously, these are only to be considered theoretical forecasting estimations, but are useful to get an idea of the big concern we are addressing to date.

\section{The problem of hospitalization, caregivers availability and intensive care units (ICUs)}

Two fundamental issues make us aware of the jeopardized situation in Italy, caused also by the multi-faceted and differential decisions engaged by the various Regional Governments to facing at SARS-CoV2 pandemic and harboring citizens to their own home safety. The most recent data while we are writing this article, March 26th 2020, showed that COVID19 lethality is very high in Lumbardy $(13.9 \%)$ while is decisely lower in the neighboring Veneto, where Venice and Padua are located (4.1\%). Despite the same rate of disease occurrence, for example both Regions have $5 \%$ of ICU patients, Veneto has more than $71 \%$ of sick people assisted at home, while Lumbardy has only $46 \%$. The different Regional politics may suggest that Lumbardy mainly prefers to hospitalize symptomatic, suffering people more than giving them proper domiciliar assistance, 
Table 1 Error matrix in the COVID19 diagnosis*

\begin{tabular}{|c|c|c|c|c|c|c|c|c|c|c|c|}
\hline $\begin{array}{l}\text { True } \\
\text { positive } \\
\text { false } \\
\text { positive }\end{array}$ & $\begin{array}{l}\text { True } \\
\text { negative } \\
\text { false } \\
\text { negative }\end{array}$ & Sensitivity & Specificity & Precision & $\begin{array}{l}\text { Negative } \\
\text { predictive } \\
\text { value }\end{array}$ & $\begin{array}{l}\mathrm{FP} \\
\text { rate }\end{array}$ & $\begin{array}{l}\text { False } \\
\text { discovery } \\
\text { rate }\end{array}$ & $\begin{array}{l}\text { False } \\
\text { negative } \\
\text { rate }\end{array}$ & Accuracy & $\begin{array}{l}\text { F1 } \\
\text { score }\end{array}$ & $\begin{array}{l}\text { Matthews } \\
\text { correlation } \\
\text { coefficient }\end{array}$ \\
\hline $\begin{array}{r}\text { Deaths } \\
9134 \\
7808\end{array}$ & $\begin{array}{l}\text { Deaths } \\
10,950 \\
291\end{array}$ & 0.9691 & 0.5838 & 0.5391 & 0.9741 & 0.4162 & 0.4609 & 0.0309 & 0.7126 & 0.6928 & 0.5327 \\
\hline $\begin{array}{r}\text { Positive } \\
86,498 \\
10,307\end{array}$ & $\begin{array}{l}\text { Positive } \\
307,581 \\
110,823\end{array}$ & 0.4384 & 0.9676 & 0.8935 & 0.7351 & 0.0324 & 0.1065 & 0.5616 & 0.7649 & 0.5882 & 0.5052 \\
\hline $\begin{array}{l}\text { ICU } \\
3732 \\
219\end{array}$ & $\begin{array}{c}\text { ICU } \\
755 \\
1844\end{array}$ & 0.6693 & 0.7752 & 0.9446 & 0.2905 & 0.2248 & 0.0554 & 0.3307 & 0.6850 & 0.7835 & 0.3232 \\
\hline
\end{tabular}

*data elaborated from results provided from the Italian Ministry of Health

particularly if we observe than the distribution of elderly people in those Regions is homogenously widespread, amounting to about 20-22\% for both, respectively (Institute of STATistics, ISTAT data).

Hospitalization may be obviously a crucial and urgent practice to be held but increases the risk to catch a nosocomial (iatrogen) disease, which highly reduces patients' survival expectancy, increases the potential number of subjects undergoing SARS-CoV2 infection, and moreover enhances the risk to fail crucial decisions due to the high bias incidence associated with emergency [50-52]. A recent report suggests a protocol to keep away COVID19 from hospitals [52]. Here the author suggests to assess people suspected to have COVID-19, swabbed and make them assisted by specially trained paramedics in high protective equipment, rather than hospitalize them [52]. The consideration of hospital-mediated infectios, either bacteria, fungi or virus, is crucial to foresee the exacerbation of the SARS-CoV2 infected patient in a hospitalized situation. As outlined before, SARS-CoV2 virulence targets an impaired pulnomary microbiome to exacerbate the purported COVID19 clinical manifestation.

Table 1 shows the performance evaluation (error matrix) [53] of medical diagnosis when taking into consideration some parameters as absolutely informative of an assessed COVID19. According to this evaluation and based on the latest available data (March 27th 2020), deaths following a COVID19-positive test have the highest priority in claiming a COVID19 infection, whereas COVID19 positivity is the lowest. This raises a fundamental bias in managing medical emergency, i.e. mainly focusing onto positive subjects as potential ICU-dead warnings, driving many medical decisions to emphasize or preferentially select hospitalization. In this circumstance a whasover positive subject can be biased in his symptoms, by overestimating them. This may occur to prevent crowding in ICUs by highly monitoring and treating with available drugs the paucisymptomatic or mild symptomatic patient. Although test positive people suffering from purported COVID19 symptoms may not be really sick for COVID19 (sensitivity 43.84\%) despite the high precision of the test $(89.35 \%)$, deaths diagnosed for COVID19 have a small precision $(53.91 \%)$, so suggesting that a certain percentage of reported deaths may undergo interstitial severe pneumonia from ethiopathogenetic causes other than COVID19 (Table 1).

\section{Concluding remarks}

The correct evaluation of the COVID19 emergency in Italy is still a big concern. Virus biology and its ability to widesprad within the population, needs to be further elucidated but this urgently asks for a much more caution to enterprise any Government decision, as many possible foes and biased interpretations are included in the risk evaluation of pandemic. Further research on this crucal issue will give us insightful clues about the complex mechanisms triggeted by SARS-CoV2 and enable all of us to better face at its virulence in the forthcoming days.

\section{Compliance with ethical standards}

Conflict of interest The authors state thay have no conflict of interest.

\section{References}

1. WHO Coronavirus disease (COVID-2019) situation reports. Situation report-9. $2020 \mathrm{https} / /$ www.who.int/emergencies/diseases/ novel-coronavirus-2019/situation-reports/ 
2. WHO Coronavirus disease (COVID-2019) situation reports. Situation report-11 https://www.who.int/emergencies/diseases/ novel-coronavirus-2019/situation-reports/

3. Spiteri G, Fielding J, Diercke M, Campese C, Enouf V, Gaymard A, Bella A, Sognamiglio P, Sierra Moros MJ, Riutort AN, Demina YV, Mahieu R, Broas M, Bengnér M, Buda S, Schilling J, Filleul L, Lepoutre A, Saura C, Mailles A, Levy-Bruhl D, Coignard B, Bernard-Stoecklin S, Behillil S, van der Werf S, Valette M, Lina B, Riccardo F, Nicastri E, Casas I, Larrauri A, Salom Castell M, Pozo F, Maksyutov RA, Martin C, Van Ranst M, Bossuyt N, Siira L, Sane J, Tegmark-Wisell K, Palmérus M, Broberg EK, Beauté J, Jorgensen P, Bundle N, Pereyaslov D, Adlhoch C, Pukkila J, Pebody R, Olsen S, Ciancio BC. First cases of coronavirus disease 2019 (COVID-19) in the WHO European Region, 24 January to 21 February 2020. Euro Surveill. 2020;25(9):2000178. https://doi.org/10.2807/1560-7917.ES. 2020.25.9.2000178.

4. Lai A, Bergna A, Acciarri C, Galli M, Zehender G. Early phylogenetic estimate of the effective reproduction number of SarsCoV-2. J Med Virol. 2020. https://doi.org/10.1002/jmv.25723.

5. Rochon J, Gondan M, Kieser M. To test or not to test: Preliminary assessment of normality when comparing two independent samples. BMC Med Res Methodol. 2012;19(12):81.

6. Holt CC. Forecasting seasonals and trends by exponentially weighted moving averages, ONR Research Memorandum, Carnegie Institute 52, 1957.

7. Maranzano P, Fassò A, Pelagatti M, Mudelsee AM. Statistical modeling of the early-stage impact of a new traffic policy in Milan, Italy. Int J Environ Res Public Health. 2020;17(3):1088.

8. Carugno M, Consonni D, Randi G, Catelan D, Grisotto L, Bertazzi PA, Biggeri A, Baccini M. Air pollution exposure, causespecific deaths and hospitalizations in a highly polluted Italian region. Environ Res. 2016;147:415-24.

9. Lai CC, Liu YH, Wang CY, Wang YH, Hsueh SC, Yen MY, Ko WC, Hsueh PR. Asymptomatic carrier state, acute respiratory disease, and pneumonia due to severe acute respiratory syndrome coronavirus 2 (SARS-CoV-2): Facts and myths. J Microbiol Immunol Infect. 2020

10. Lupia T, Scabini S, Mornese Pinna S, Di Perri G, De Rosa FG, Corcione S. 2019 novel coronavirus (2019-nCoV) outbreak: a new challenge. J Glob Antimicrob Resist. 2020;21:22-7. https:// doi.org/10.1016/j.jgar.2020.02.021.

11. Gupta R, Ghosh A, Singh AK, Misra A. Clinical considerations for patients with diabetes in times of COVID-19 epidemic. Diabetes Metab Syndr. 2020;14(3):211-2.

12. Conti S, Harari S, Caminati A, Zanobetti A, Schwartz JD, Bertazzi PA, Cesana G, Madotto F. The association between air pollution and the incidence of idiopathic pulmonary fibrosis in Northern Italy. Eur Respir J. 2018;51(1):1700397. https://doi.org/ 10.1183/13993003.00397-2017.

13. Wuyts WA, Cavazza A, Rossi G, Bonella F, Sverzellati N, Spagnolo P. Differential diagnosis of usual interstitial pneumonia: when is it truly idiopathic? Eur Respir Rev. 2014;23(133):308-19.

14. Guo L, Ren L, Yang S, Xiao M, Chang, Yang F, Dela Cruz CS, Wang Y, Wu C, Xiao Y, Zhang L, Han L, Dang S, Xu Y, Yang Q, Xu S, Zhu H, Xu Y, Jin Q, Sharma L, Wang L, Wang J. Profiling early humoral response to diagnose novel coronavirus disease (COVID-19). Clin Infect Dis. 2020;ciaa310. https://doi. org/10.1093/cid/ciaa310.

15. He F, Deng Y, Li W. Coronavirus disease 2019 (COVID-19): what we know? J Med Virol. 2020. https://doi.org/10.1002/jmv. 25766.

16. Salisbury ML, Han MK, Dickson RP, Molyneaux PL. Microbiome in interstitial lung disease: from pathogenesis to treatment target. Curr Opin Pulm Med. 2017;23(5):404-10.
17. Fastrès A, Felice F, Roels E, Moermans C, Corhay JL, Bureau F, Louis R, Clercx C, Guiot J. The lung microbiome in idiopathic pulmonary fibrosis: a promising approach for targeted therapies. Int J Mol Sci. 2017;18(12):2735. https://doi.org/10.3390/ ijms18122735.

18. Travis WD, Costabel U, Hansell DM, King TE Jr, Lynch DA, Nicholson AG, et al. An official American thoracic society/ European respiratory society statement: Update of the international multidisciplinary classification of the idiopathic interstitial pneumonias. Am J Respir Crit Care Med. 2013;188(6):733-48.

19. Tang YW, Johnson JE, Browning PJ, Cruz-Gervis RA, Davis A, Graham BS, et al. Herpesvirus DNA is consistently detected in lungs of patients with idiopathic pulmonary fibrosis. J Clin Microbiol. 2003;41(6):2633-40.

20. Richter AG, Stockley RA, Harper L, Thickett DR. Pulmonary infection in Wegener granulomatosis and idiopathic pulmonary fibrosis. Thorax. 2009;64(8):692-7.

21. Habibzadeh P, Stoneman EK. The novel coronavirus: a bird's eye view. Int J Occup Environ Med. 2020;11(2):65-71.

22. Goh KJ, Choong MC, Cheong EH, Kalimuddin S, Duu Wen S, Phua GC, Chan KS, Haja MS. Rapid progression to acute respiratory distress syndrome: review of current understanding of critical illness from covid-19 infection. Ann Acad Med Singapore. 2020;49(1):1-9.

23. Martin-Loeches I, Rodriguez AH, Torres A. New guidelines for hospital-acquired pneumonia/ventilator-associated pneumonia: USA vs. Europe Curr Opin Crit Care. 2018;24(5):347-52.

24. Bassetti M, Righi E, Vena A, Graziano E, Russo A, Peghin M. Risk stratification and treatment of ICU-acquired pneumonia caused by multidrug-resistant/extensively drug-resistant/pandrugresistant bacteria. Curr Opin Crit Care. 2018;24(5):385-93.

25. Lanks CW, Musani AI, Hsia DW. Community-acquired pneumonia and hospital-acquired pneumonia. Med Clin North Am. 2019;103(3):487-501.

26. Chen J, Lau YF, Lamirande EW, Paddock CD, Bartlett JH, Zaki SR, Subbarao K. Cellular immune responses to severe acute respiratory syndrome coronavirus (SARS-CoV) infection in senescent BALB/c mice: CD4+ T cells are important in control of SARS-CoV infection. J Virol. 2010;84(3):1289-301.

27. Conti P, Ronconi G, Caraffa A, Gallenga CE, Ross R, Frydas I, Kritas SK. Induction of pro-inflammatory cytokines (IL-1 and IL6) and lung inflammation by Coronavirus-19 (COVI-19 or SARSCoV-2): anti-inflammatory strategies. J Biol Regul Homeost Agents. 2020

28. Vicenzi E, Canducci F, Pinna D, Mancini N, Carletti S, Lazzarin A, Bordignon C, Poli G, Clementi M. Coronaviridae and SARSassociated coronavirus strain HSR1. Emerg Infect Dis. 2004;10(3):413-8.

29. Rezza G, Marino R, Farchi F, Taranto M. SARS epidemic in the press. Emerg Infect Dis. 2004;10(2):381-2.

30. Dy R, Sethi S. The lung microbiome and exacerbations of COPD. Curr Opin Pulm Med. 2016;22(3):196-202.

31. Li KJ, Chen ZL, Huang Y, Zhang R, Luan XQ, Lei TT, Chen L. Dysbiosis of lower respiratory tract microbiome are associated with inflammation and microbial function variety. Respir Res. 2019;20(1):272.

32. Chen D, Xiao C, Jin H, Yang B, Niu J, Yan S, Sun Y, Zhou Y, Wang $\mathrm{X}$. Exposure to atmospheric pollutants is associated with alterations of gut microbiota in spontaneously hypertensive rats. Exp Ther Med. 2019;18(5):3484-92.

33. Chen HI, Kao SJ, Wang D, Lee RP, Su CF. Acute respiratory distress syndrome. J Biomed Sci. 2003;10(6 Pt 1):588-92.

34. Akerström S, Gunalan V, Keng CT, Tan YJ, Mirazimi A. Dual effect of nitric oxide on SARS-CoV replication: viral RNA production and palmitoylation of the $\mathrm{S}$ protein are affected. Virology. 2009;395(1):1-9. 
35. Imai Y, Kuba K, Rao S, Huan Y, Guo F, Guan B, Yang P, Sarao R, Wada T, Leong-Poi H, Crackower MA, Fukamizu A, Hui CC, Hein L, Uhlig S, Slutsky AS, Jiang C, Penninger JM. Angiotensin-converting enzyme 2 protects from severe acute lung failure. Nature. 2005;436(7047):112-6.

36. Wu D, Wu T, Liu Q, Yang Z. The SARS-CoV-2 outbreak: what we know. Int J Infect Dis. 2020;S1201-9712(20):30123-5.

37. Riou J, Althaus CL. Pattern of early human-to-human transmission of Wuhan 2019 novel coronavirus (2019-nCoV), December 2019 to January 2020. Euro Surveill. 2020. https://doi.org/10. 2807/1560-7917.ES.2020.25.4.2000058.

38. Li Q, Guan X, Wu P, Wang X, Zhou L, Tong Y, Ren R, Leung KSM, Lau EHY, Wong JY, Xing X, Xiang N, Wu Y, Li C, Chen Q, Li D, Liu T, Zhao J, Li M, Tu W, Chen C, Jin L, Yang R, Wang Q, Zhou S, Wang R, Liu H, Luo Y, Liu Y, Shao G, Li H, Tao Z, Yang Y, Deng Z, Liu B, Ma Z, Zhang Y, Shi G, Lam TTY, Wu JTK, Gao GF, Cowling BJ, Yang B, Leung GM, Feng Z. Early transmission dynamics in Wuhan, China, of novel coronavirus-infected pneumonia. N Engl J Med. 2020. https://doi. org/10.1056/NEJMoa2001316.

39. Wu JT, Leung K, Bushman M, et al. Estimating clinical severity of COVID-19 from the transmission dynamics in Wuhan. China Nat Med. 2020. https://doi.org/10.1038/s41591-020-0822-7.

40. Report of the WHO-China Joint Mission on Coronavirus Disease. https://www.who.int/docs/default-source/coronaviruse/whochina-joint-mission-on-covid-19-final-report.pdf Date: 2019

41. van Doremalen N, Bushmaker T, Morris DH, Holbrook MG, Gamble A, Williamson BN, Tamin A, Harcourt JL, Thornburg NJ, Gerber SI, Lloyd-Smith JO, de Wit E, Munster VJ. Aerosol and surface stability of SARS-CoV-2 as compared with SARSCoV-1. N Engl J Med. 2020. https://doi.org/10.1056/ NEJMc2004973.

42. Guerra FM, Bolotin S, Lim G, Heffernan J, Deeks SL, Li Y, Crowcroft NS. The basic reproduction number $(\mathrm{R}(0))$ of measles: a systematic review. Lancet Infect Dis. 2017;17(12):e420e428428.

43. Bai Y, Yao L, Wei T, Tian F, Jin DY, Chen L, Wang M. Presumed asymptomatic carrier transmission of COVID-19. JAMA. 2020. https://doi.org/10.1001/jama.2020.2565.
44. Rothe C, Schunk M, Sothmann P, Bretzel G, Froeschl G, Wallrauch C, Zimmer T, Thiel V, Janke C, Guggemos W, Seilmaier M, Drosten C, Vollmar P, Zwirglmaier K, Zange S, Wölfel R, Hoelscher M. Transmission of 2019-nCoV infection from an asymptomatic contact in Germany. $\mathrm{N}$ Engl $\mathrm{J}$ Med. 2020;382(10):970-1.

45. Lu S, Lin J, Zhang Z, Xiao L, Jiang Z, Chen J, Hu C, Luo S. Alert for non-respiratory symptoms of coronavirus disease 2019 (covid-19) patients in epidemic period: a case report of familial cluster with three asymptomatic covid-19 patients. J Med Virol. 2020. https://doi.org/10.1002/jmv.25776.

46. Nishiura H, Kobayashi T, Suzuki A, Jung SM, Hayashi K, Kinoshita R, Yang Y, Yuan B, Akhmetzhanov AR, Linton NM, Miyama T. Estimation of the asymptomatic ratio of novel coronavirus infections (COVID-19). Int J Infect Dis. 2020;94:154-5. https://doi.org/10.1016/j.ijid.2020.03.020.

47. Choi SC, Ki M. Estimating the reproductive number and the outbreak size of Novel Coronavirus disease (COVID-19) using mathematical model in Republic of Korea. Epidemiol Health. 2020;12:e2020011.

48. Stojanović O, Leugering J, Pipa G, Ghozzi S, Ullrich A. A Bayesian Monte Carlo approach for predicting the spread of infectious diseases. PLoS ONE. 2019;14(12):e0225838.

49. Li X, Wang W, Zhao X, Zai J, Zhao Q, Li Y, Chaillon A. Transmission dynamics and evolutionary history of 2019-nCoV. J Med Virol. 2020;92(5):501-11.

50. Glasper A. Keeping patients safe from hospital-acquired infection. Br J Nurs. 2019;28(13):890-1.

51. Taylor ME, Oppenheim BA. Hospital-acquired infection in elderly patients. J Hosp Infect. 1998;38(4):245-60.

52. Glauser W. Proposed protocol to keep COVID-19 out of hospitals. CMAJ. 2020;192(10):E264-E265265.

53. Xuanyang X, Yuchang G, Shouhong W, Xi L. Computer aided detection of sars based on radiographs data mining. Conf Proc IEEE Eng Med Biol Soc. 2005;2005:7459-62.

Publisher's Note Springer Nature remains neutral with regard to jurisdictional claims in published maps and institutional affiliations. 